\title{
CURRENT PRE-OPERATIVE TESTING PRACTICES IN AMBULATORY SURGERY ARE WIDELY DISPARATE: A SURVEY OF CAS MEMBERS
}

\author{
Hongbo Yuan MD Ph.D., Frances Chung MD, David Wong MD and Reginald Edward \\ Department of Anesthesia, Toronto Western Hospital, University of Toronto, 399 Bathurst St., \\ Toronto, Ontario, M5T 2S8
}

INTRODUCTION: Routine preoperative testing has been criticized as having little impact on perioperative outcomes. The purpose of this study is to identify the current practice of preoperative testing in ambulatory surgery.

METHODS: A standard questionnaire was sent to all active members of the Canadian Anesthesiologists' Society (CAS) after Institutional Ethics Board approval. The study inquired into the anesthesiologist's preoperative testing practice in healthy patients and patients with stable medical conditions undergoing ambulatory surgery.

RESULTS: A total 617 respondents who reported their participation in ambulatory surgical care were received. Eighty percent (95\% CI 76.5-83.2) of the respondents indicated that, if testing had to be ordered in asymptomatic patients undergoing low-risk ambulatory surgery, it would be due to the patient's clinical indications while others indicated it would be the result of following institutional guidelines $(15.1 \%, 95 \%$ CI 12.2-17.9), and even fewer attributed it to a 'routine' testing practice $(0.5 \%, 95 \%$ CI $0-1.14)$. Forty-four percent $(95 \%$ CI 39.8-47.8) of the anesthesiologists indicated that age alone is not a criterion when they required a preoperative ECG while others reported various cutpoints $(>65 ;>55 ;>45 ;>40$ years) for ECG ordering for asymptomatic patients undergoing the low-risk ambulatory surgery (see figure). Forty percent (95\% CI 35.7-43.5) of the anesthesiologists had no specific concern regarding eliminating preoperative testing in ambulatory surgery.

DISCUSSION: Our survey has documented marked disparities in the practices of preoperative testing. The practice of ordering preoperative ECG varied according to different age categories. A large proportion of the anesthesiologists indicated that age alone should not be a criterion for preoperative ordering of ECG. In fact, the new ACC/AHA guideline updates indicate that 'routine' ECG in the asymptomatic male $>45$ years of age or female $>55$ years of age is not supported unless combined with 2 or more atherosclerotic risk factors. ${ }^{1}$ In Ontario, the high vs low rate in ECG use has not corresponded with any recognizable difference in perioperative patient outcomes between institutions. ${ }^{2}$ Preoperative testing may be eliminated in low-risk ambulatory surgery when clear evidence is obtained.

\section{REFERENCE:}

1. J Am Coll Cardiol 39:542-53

2. Hosp Q. 6 (4):26-7 
Age alone as a criterion for preoperative ordering of ECG in asymptomatic patients undergoing low-risk ambulatory surgery

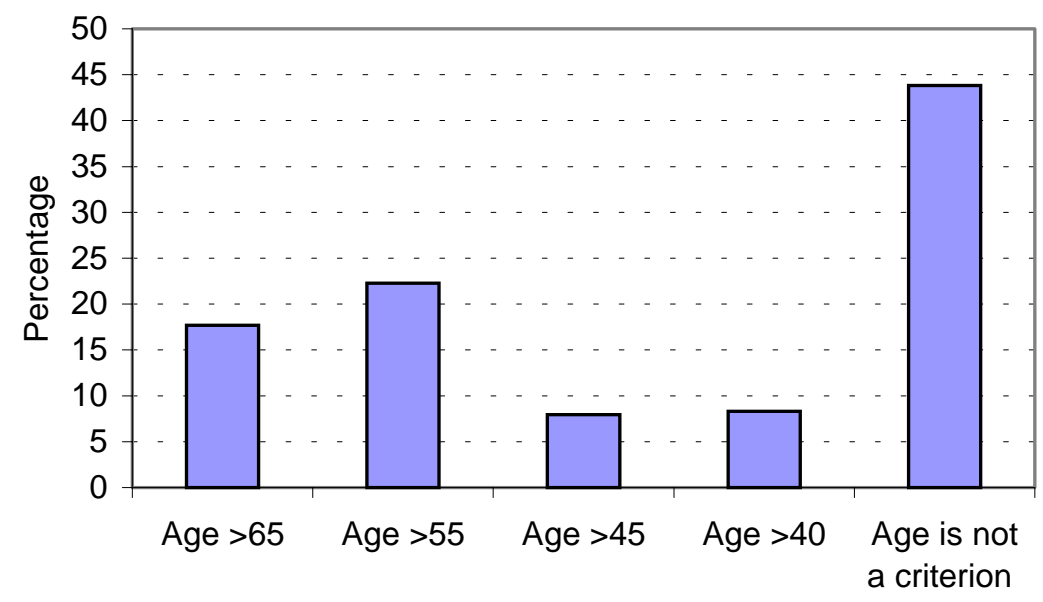

